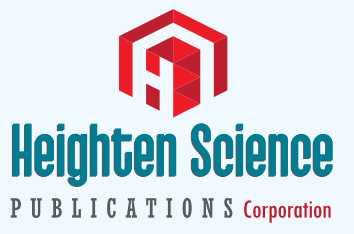

ISSN

2573-7724

\title{
Percentage of Positive Biopsy Cores Predicts Presence of a Dominant Lesion on MRI in Patients with Intermediate Risk Prostate Cancer
}

\author{
Jason M Slater ${ }^{1}$, William W Millard ${ }^{2}$, Samuel M Randolph², \\ Thomas J Kelly ${ }^{2}$ and David A Bush ${ }^{1 *}$ \\ 'Departments of Radiation Medicine, Loma Linda University, Loma Linda, California, USA \\ ${ }^{2}$ Departments of Radiology, Loma Linda University, Loma Linda, California, USA
}

\begin{abstract}
*Address for Correspondence: David A Bush, MD, Department of Radiation Medicine, Loma Linda University Medical Center, 11234 Anderson Street, Loma Linda, CA 92354, USA, Tel: 909-558-4280;

E-mail: dbush@llu.edu
\end{abstract}

Submitted: 08 October 2018

Approved: 11 October 2018

Published: 12 October 2018

Copyright: (C) 2018 Slater JM, et al. This is an open access article distributed under the Creative Commons Attribution License, which permits unrestricted use, distribution, and reproduction in any medium, provided the original work is properly cited

Keywords: Prostate cancer; Biopsy cores; MRI; Prognosis; Multivariate analysis

Check for updates

\section{Abstract}

Background: Biopsy findings of percentage of positive biopsy cores, percentage of cancer volume, and maximum involvement of biopsy cores have been shown to have prognostic value and correlate with magnetic resonance imaging (MRI) findings of extracapsular extension and seminal vesicle invasion. The relationship of these prognostic biopsy factors to MRI findings of the presence of a dominant lesion, has not yet been investigated.

Methods: Sixty-five patients with intermediate risk prostate cancer were included in a retrospective cohort. MRI was acquired using either $1.5 \mathrm{Tesla}(\mathrm{T})$ with endorectal coil or a 3 T MRI unit. Findings of extracapsular extension, seminal vesicle invasion, and presence and number of dominant lesions were noted. T-test and Cox regression statistical analyses were performed.

Results: Patients with one or more dominant lesions on MRI had a significantly higher mean percentage of positive biopsy cores $(56.7 \%$ vs $39.8 \%, p=0.004)$, percentage of cancer volume ( $23.5 \%$ vs $14.5 \%, p=0.011)$ and maximum involvement of biopsy cores $(62.9 \%$ vs $47.3 \%, p=0.027)$ than those without a dominant lesion on MRI. On multivariate analysis, only percentage of positive biopsy cores remained a statistically significant predictor for a dominant lesion on MRI (Hazard Ratio 1.06 [95\% Cl 1.01-1.12; $\mathrm{p}=0.02]$ ), whereas prostate-specific antigen, clinical T-stage, Gleason score, percentage of cancer volume, and maximum involvement of biopsy cores were not significant predictors of a dominant lesion on MRI. Receiver-operator characteristic analysis was done and a cutoff value of $>=50 \%$ was chosen for percentage of positive biopsy cores, $>=15 \%$ for percentage of cancer volume, $>=50 \%$ for maximum involvement of biopsy cores.

Conclusion: Percentage of positive biopsy cores was found to be a significant predictor for the presence of a dominant lesion on MRI. This finding is hypothesis-generating and should be confirmed with a prospective trial.

\section{Introduction}

Risk stratification for prostate cancer utilizes well-established parameters of T stage, Gleason score, and prostate-specific antigen (PSA) level [1]. More recently, additional factors such as the percentage of positive biopsy cores (PPCs), percentage of cancer volume (PCV), and maximum involvement of biopsy cores (MIBC) have been shown to have prognostic value, particularly in National Comprehensive Cancer Network (NCCN) intermediate risk patients [2-5]. Magnetic resonance imaging (MRI) of the prostate has been shown to have prognostic significance [6-9] and has been shown to correlate with various prognostic factors seen on biopsy [10-13]. These studies have evaluated prognostic factors and MRI findings of extracapsular extension (ECE) and 
seminal vesicle invasion (SVI); however, the relationship of these prognostic factors with the finding of a dominant lesion on MRI has not been yet investigated, nor has the comparison of PPC, PCV, and MIBC with MRI findings. Therefore, we assessed the role of PPC, PCV, and MIBC on not only MRI findings of ECE and SVI, but also on the presence and number of dominant lesions. We focused specifically on intermediate-risk patients.

\section{Methods}

Sixty-five patients with clinically localized intermediate-risk category prostate cancer, who had undergone high-field-strength pretreatment MRI scans performed during a predefined time frame (2007-2011), were selected for a retrospective cohort study. Approval for this study was obtained from the Loma Linda University Institutional Review Board. Patients had to have pathology reports with information necessary to calculate PPC, PCV, and MIBC, including the percentage of cancer reported in each core and the total number of biopsy cores taken. These parameters have been previously defined [2-4,14]. Patients starting androgen deprivation therapy prior to undergoing prostate MRI were excluded.

\section{MRI}

Images were acquired using either a 1.5 Tesla or 3 Tesla MRI unit. Patients were imaged in the supine position. Patients who underwent imaging with $1.5 \mathrm{~T}$ did so with an endorectal coil; those with $3 \mathrm{~T}$ imaging did so without an endorectal coil. Cases were reviewed by two body trained radiologists with, respectively, 22 years and five years of experience. Readers were aware that the patients had prostate cancer as per routine, but were blinded to other clinical information such as PSA and Gleason score. Reader consensus was obtained at the time of readout regarding presence of extracapsular extension, seminal vesicle invasion, and presence of disease in each sextant by T2 and advanced diffusion coefficient (ADC) imaging, including the presence of one or more dominant lesions. The term, "dominant lesion," has been previously defined with some variability [7,12,15-17], we defined it as a moderately well-defined focus of T2 hypointensity within the prostate peripheral zone.

\section{Statistical analysis}

Results were analyzed for association between these findings on MRI and the results of clinical and pre-treatment prostate biopsy data, including PSA, Gleason Score, T stage, PCV, PPC, and MIBC. Statistical analysis was performed utilizing independentsamples t-test, Spearman's correlation, logistic regression, and contingency tables. A receiver-operator characteristic (ROC) analysis was done in an effort to define clinical cutoffs for PPC, PCV, and MIBC. Analysis was performed using SPSS statistical software.

\section{Results}

Sixty-five patients were identified for this study. One was excluded because he was found to be in the NCCN low-risk category and two were excluded because they had started androgen deprivation therapy prior to undergoing prostate MRI, leaving 62 patients available for analysis. Clinical and pathologic characteristics are listed in table 1.

Most patients (87\%) had a Gleason score of 7; 65\% were Gleason grade group 2 $(3+4=7)$ and $23 \%$ were Gleason grade group $3(4+3=7)$. The median PSA was $6.7 \mathrm{ng} /$ $\mathrm{mL}$ with a range of $0.7-16.5 \mathrm{ng} / \mathrm{mL}$. Approximately half of the patients $(52 \%)$ were stage T1c with a smaller percentage being T2a (25\%), T2b (18\%), and T2c (7\%). Sixtyone percent of patients had a PPC of at least $50 \%$ with a mean value of $50 \%$; the mean PCV was $17.3 \%$, and the mean MIBC was $60 \%$.

\section{MRI Findings}

Complete MRI findings are listed in table 2. Thirty-nine patients (63\%) were found to have at least one dominant lesion on MRI. Twenty-four patients (39\%) were found 


\begin{tabular}{|c|c|c|}
\hline Characteristic & Number $(n=62)$ & $\%$ \\
\hline Age (y), median (range) & 66 & $(52-81)$ \\
\hline PSA (ng/mL), median (range) & 6.7 & $(0.7-16.50)$ \\
\hline \multicolumn{3}{|c|}{ Clinical T stage (by physical examination) } \\
\hline $\mathrm{T} 1 \mathrm{c}$ & 32 & $51.6 \%$ \\
\hline $\mathrm{T} 2 \mathrm{a}$ & 15 & $24.2 \%$ \\
\hline $\mathrm{T} 2 \mathrm{~b}$ & 11 & $17.7 \%$ \\
\hline $\mathrm{T} 2 \mathrm{c}$ & 4 & $6.5 \%$ \\
\hline \multicolumn{3}{|c|}{ Gleason score } \\
\hline $3+3$ & 8 & $12.9 \%$ \\
\hline $3+4$ & 40 & $64.5 \%$ \\
\hline $4+3$ & 14 & $22.6 \%$ \\
\hline PPC, median (range) & $50.00 \%$ & $(7.1-100 \%)$ \\
\hline$<50 \%$ & 24 & $38.7 \%$ \\
\hline$\geq 50 \%$ & 38 & $61,3 \%$ \\
\hline PCV, median (range) & $17.25 \%$ & $(0.4-54.2 \%)$ \\
\hline$<22.5 \%$ & 37 & $59.7 \%$ \\
\hline$\geq 22.5 \%$ & 25 & $40.3 \%$ \\
\hline MIBC, median (range) & $60.00 \%$ & $(5-100 \%)$ \\
\hline$>60 \%$ & 30 & $48.4 \%$ \\
\hline$\geq 60 \%$ & 32 & $51.6 \%$ \\
\hline
\end{tabular}

Table 2: MRI findings.

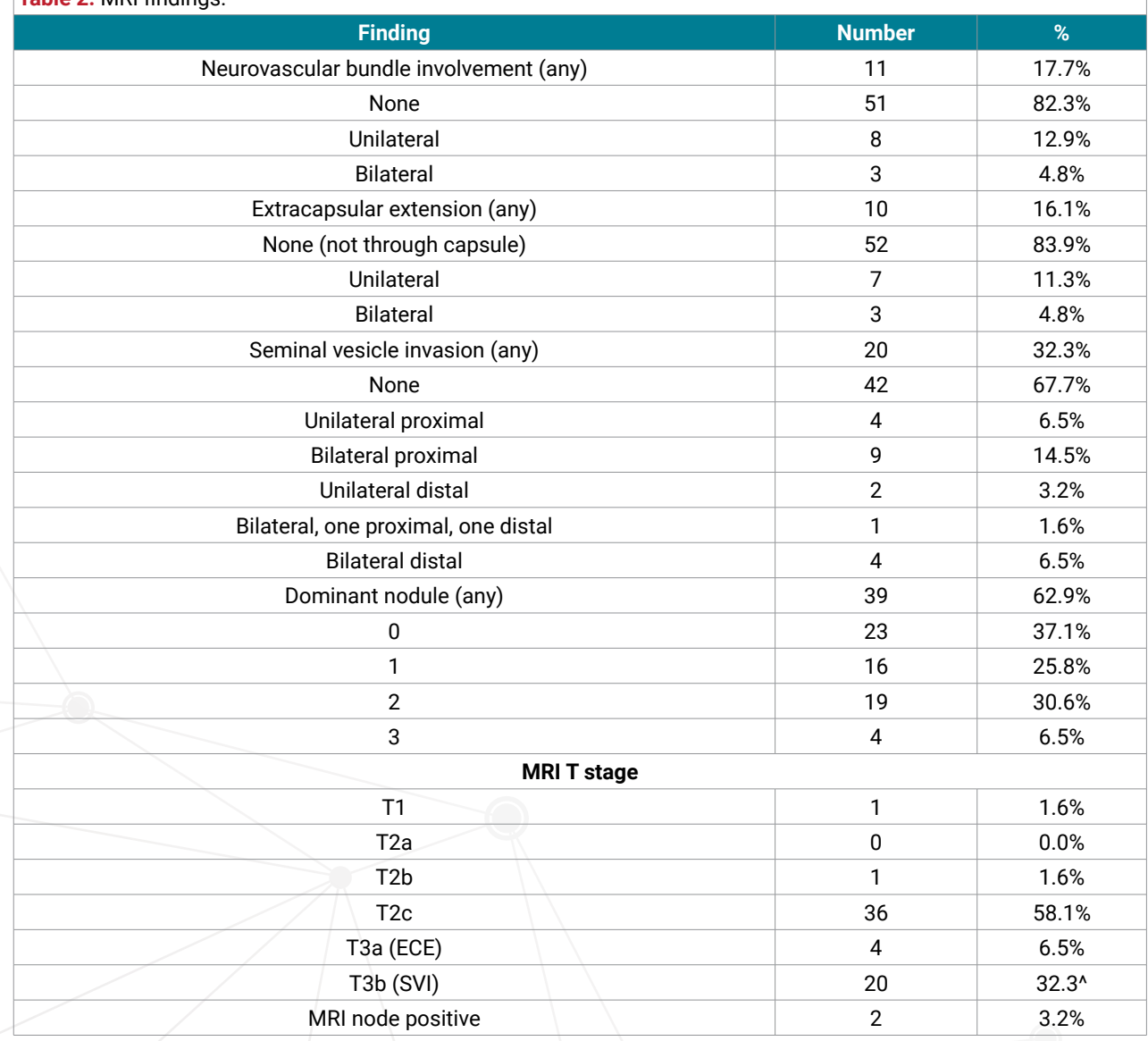

to have stage T3 disease on MRI, four patients had extracapsular extension only, 14 patients had seminal vesicle invasion alone, and six patients had both ECE and SVI. Two patients were found to have node-positive disease.

\section{Variables associated with MRI findings}

Established prognostic factors of PSA, T Stage, and Gleason score were not found to be statistically significant predictors of MRI findings, including the presence of 
a dominant lesion, the number of dominant lesions, neurovascular bundle (NVB) involvement, extracapsular extension (ECE), or seminal vesicle invasion (SVI).

Patients with one or more dominant lesions on MRI had a significantly higher mean PPC $(56.7 \%$ vs $39.8 \%, \mathrm{p}=0.004)$, PCV $(23.5 \%$ vs $14.5 \%, \mathrm{p}=0.011)$ and MIBC $(62.9 \%$ vs $47.3 \%, p=0.027$ ) than those without a dominant lesion on MRI. Curiously, patients with evidence of SVI on MRI had a lower mean PCV compared to those who did not have evidence of SVI ( $14.8 \%$ vs $22.8 \%$, $p=0.023)$. Otherwise, no statistically significant difference was seen in the mean values of PPC, PCV, or MIBC when evaluating the presence or absence of SVI, ECE, or NVB involvement on MRI.

Next, receiver-operator characteristic (ROC) analysis was done in an effort to define clinical cutoffs for PPC, PCV, and MIBC, which could be utilized for predicting a dominant lesion. Again, all three variables were found to predict the presence of a dominant lesion (Area under the curve 0.71, $\mathrm{p}=0.005 ; 0.69, \mathrm{p}=0.011$; and $0.67, \mathrm{p}=0.028$ respectively). PPC of $>=50 \%$, PCV $>=15 \%$ and MIBC of $>=50 \%$ were determined to be optimal cut points based on ROC analysis. Contingency tables were constructed (Table 3 ) and chi-square analysis was done using these cutoffs.

On multivariate analysis, only PPC remained a statistically significant predictor of a dominant lesion on MRI, whereas PSA, Clinical T-stage, Gleason score, PCV, and MIBC were not significant predictors of such a lesion (Table 4).

\section{Discussion}

Intermediate risk prostate cancer patients comprise a heterogeneous population in terms of survival. Others have attempted to additionally stratify intermediate risk patients by using various clinical factors such as a primary Gleason score of 4, PPC $>=50 \%$, and the presence of multiple intermediate risk features [18]. Because of the

\begin{tabular}{|c|c|c|c|}
\hline & No dominant lesion & Dominant lesion & p value \\
\hline $\mathrm{N}$ & 23 & 39 & \\
\hline \multicolumn{3}{|c|}{ Clinical T stage } & 0.44 \\
\hline T1c & 15 & 17 & \\
\hline $\mathrm{T} 2 \mathrm{a}$ & 4 & 11 & \\
\hline $\mathrm{T} 2 \mathrm{~b}$ & 3 & 8 & \\
\hline $\mathrm{T} 2 \mathrm{c}$ & 1 & 3 & \\
\hline \multicolumn{3}{|c|}{ Gleason score } & 0.27 \\
\hline Grade group $1(3+3=6)$ & 5 & 3 & \\
\hline Grade group $2(3+4=7)$ & 13 & 27 & \\
\hline Grade group $3(4+3=7)$ & 5 & 9 & \\
\hline \multicolumn{3}{|c|}{ Percentage of positive cores } & 0.008 \\
\hline$<50 \%$ & 14 & 10 & \\
\hline$\geq 50 \%$ & 9 & 29 & \\
\hline \multicolumn{3}{|c|}{ Percentage of cancer volume } & 0.016 \\
\hline$<15 \%$ & 14 & 11 & \\
\hline$\geq 15 \%$ & 9 & 28 & \\
\hline \multicolumn{3}{|c|}{ Maximum involvement of biopsy core } & 0.034 \\
\hline$<50 \%$ & 13 & 11 & \\
\hline$\geq 50 \%$ & 10 & 28 & \\
\hline $\mathrm{PSA}(\mathrm{ng} / \mathrm{mL})$, mean $\pm \mathrm{SD}$ & $7.43 \pm 4.05$ & $7.27 \pm 3.13$ & 0.86 \\
\hline
\end{tabular}

Table 4: Multivariate logistic regression analysis of factors associated with dominant lesion on MRI.

\begin{tabular}{|c|c|c|c|}
\hline & p value & Odds ratio & $95 \% \mathbf{C l}$ \\
\hline Pretreatment PSA & 0.10 & 1.20 & $0.97-1.48$ \\
\hline Clinical T stage & 0.51 & 1.28 & $0.61-2.69$ \\
\hline Gleason score & 0.31 & 1.81 & $0.58-5.70$ \\
\hline Percentage of positive biopsy cores & 0.02 & 1.06 & $1.01-1.12$ \\
\hline Percentage of cancer volume & 0.31 & 0.95 & $0.85-1.05$ \\
\hline Maximum involvement of biopsy cores & 0.12 & 1.03 & $0.99-1.07$ \\
\hline
\end{tabular}


heterogeneous nature of this patient population, however, there is a need to further assess potential differences in patients within this intermediate-risk group in an effort to ultimately optimize patient care.

In this study of intermediate-risk prostate cancer patients we found that the risk of having a dominant lesion on MRI was significantly associated with the percentage of positive biopsy cores. Further, this risk is independent of other prognostic factors such as PSA, T stage, and Gleason score. These findings are particularly relevant to radiation therapy for prostate cancer. Given current ongoing interest in delivering additional radiation dose to MRI dominant lesions in patients with prostate cancer [17,19-21], our study provides additional data on the intermediate-risk patients who are more likely to harbor a dominant lesion and thus be candidates for this type of treatment.

The concept of a dominant MRI lesion has been described in the literature utilizing terms such as "dominant intraprostatic lesion," "dominant tumor," and "index lesion" $[7,12,15-17]$. Given that the exact definition of a dominant lesion has had some variability, in our study we defined it as a moderately well-defined focus of T2 hypointensity within the prostate peripheral zone. This typically had a gradient of demarcation with adjacent more normal-appearing gland. By contrast, any area of ill-defined T2 hypointensity within a prostate sextant was designated as having probable tumor infiltration without a nodular morphology and was classified as simply T2 hypointense.

To our knowledge, this study is the first to associate pathologic data from prostate biopsies with the presence of a dominant lesion on MRI. Previous studies have looked at various pre-clinical treatment factors and MRI findings. One study showed that PPC and perineural invasion correlated with T3 disease on MRI; however, the cohort of patients in that study included low- and high-risk groups [10], while our study focused specifically on intermediate-risk patients. Studies have attempted to integrate MRI into models utilizing biopsy data to predict more extensive disease on pathology after prostatectomy $[6,11]$. Studies have also looked at MRI findings and clinical outcomes after externalbeam radiation therapy (EBRT). One publication showed that index lesions, among other findings, were associated with worse outcomes after EBRT; however, the authors did not correlate the clinical predictors of PPC or PCV to MRI findings and outcome data [7].

Our study has some discrepancies with previously published data. First, one previous study showed that PPC predicted for the presence of T3 disease on MRI [10], a finding we did not demonstrate. One possible explanation for this is the difference in patient selection, as our study was limited to intermediate-risk patients, while the aforementioned study included a large number of low-risk patients and some high-risk patients. Another study showed that patients with SVI on MRI had higher Gleason scores and pretreatment PSAs [8], which contrasts with our findings. Again, that study included patients in low- and high-risk groups, thus emphasizing the importance of interpreting the present study in the context of intermediate risk patients.

Our study has several findings that generate hypotheses in both the pathology and the clinical management of prostate cancer. Clinical studies have shown PPC as an independent predictor of outcomes after EBRT [3.14], in our study, we have shown that PPC predicts for presence of a dominant nodule on MRI. The presence of a dominant nodule on MRI may be the reason why PPC predicts for outcomes after EBRT. A recent study on MRI-guided biopsies of these dominant lesions showed that Gleason scores of these biopsied lesions are higher than Gleason scores obtained on routine biopsy [22]. These recent findings about the underlying pathology of MRI dominant lesions, combined with the data presented in this study, may lead to further investigation of the biology of these dominant lesions and their role on the natural history of prostate cancer.

Our findings propose many hypotheses of clinical importance as well. Several clinical questions can be asked, such as: Should all patients with PPC $>=50 \%$ undergo 
MRI? Should intermediate-risk patients with dominant lesions on MRI undergo additional guided biopsies in attempt to accurately assess their Gleason score? Or should patients with dominant lesions undergo an additional radiation boost? These potential questions could be answered by future prospective studies.

This study has limitations. It is a retrospective investigation from a single institution. Another limitation is the type of imaging used. In our study, most patients underwent scans on 1.5T MRI units obtaining T2 and ADC sequences with use of an endorectal coil; however, many scans done today are multiparametric, performed on 3T MRI units, which includes additional sequences to further characterize lesions. These other parameters were not assessed in this study.

In conclusion, we were able to demonstrate a strong association of PPC and the presence of a dominant lesion on MRI in intermediate-risk patients, independent of PSA, Gleason score, and T stage. These findings suggest that PPC may help predict presence of a dominant lesion on MRI and thus help identify patients who would be candidates for radiation dose escalation treatment to the dominant lesion and/or selective biopsies of the dominant lesion. Given the retrospective nature of this study, these findings are hypothesis-generating and may guide the design of future prospective studies.

\section{Summary}

Percentage of positive biopsy cores, percentage of cancer volume, and maximum involvement of biopsy cores each have been shown to have prognostic value and correlate with magnetic resonance imaging findings of extracapsular extension and seminal vesicle invasion. However, the relationship of these prognostic biopsy factors to MRI findings of the presence of a dominant lesion, has not yet been investigated. Accordingly, we included 65 patients with intermediate-risk prostate cancer in a retrospective cohort, seeking to correlate these prognostic biopsy factors to MRI outcomes. Findings of extracapsular extension, seminal vesicle invasion, and presence and number of dominant lesions were noted. Statistical analyses were performed. We determined that patients with one or more dominant lesions on MRI had a significantly higher mean percentage of positive biopsy cores, percentage of cancer volume, and maximum involvement of biopsy cores than those without a dominant lesion on MRI. Multivariate analysis revealed that only percentage of positive biopsy cores remained a statistically significant predictor for a dominant lesion on MRI; prostate-specific antigen, clinical T-stage, Gleason score, percentage of cancer volume, and maximum involvement of biopsy cores were not significant predictors of a dominant lesion. We concluded that percentage of positive biopsy cores is a significant predictor for the presence of a dominant lesion on MRI. This hypothesis-generating finding should be confirmed in a prospective trial.

\section{References}

1. D'Amico AV, Whittington R, Malkowicz SB, Schultz D, Blank K, et al. Biochemical outcome after radical prostatectomy, external beam radiation therapy, or interstitial radiation therapy for clinically localized prostate cancer. JAMA. 1998; 280: 969-974. Ref.: https://goo.gl/1yqNnc

2. Vance SM, Stenmark MH, Blas K, Halverson S, Hamstra DA, et al. Percentage of cancer volume in biopsy cores is prognostic for prostate cancer death and overall survival in patients treated with dose-escalated external beam radiotherapy. Int J Radiat Oncol Biol Phys. 2012; 83: 940-946. Ref.: https://goo.gl/M2foMH

3. Slater JM, Bush DA, Grove R, Slater JD. The prognostic value of percentage of positive biopsy cores, percentage of cancer volume, and maximum involvement of biopsy cores in prostate cancer patients receiving proton and photon beam therapy. Technol Cancer Res Treat. 2014; 13: 227-231. Ref.: https://goo.gl/A1EFXG

4. Murgic J, Stenmark MH, Halverson S, Blas K, Feng FY, et al. The role of the maximum involvement of biopsy core in predicting outcome for patients treated with dose-escalated radiation therapy for prostate cancer. Radiat Oncol. 2012; 7: 127. Ref.: https://goo.gl/q9RhKq 
5. Nelson CP, Rubin MA, Strawderman M, Montie JE, Sanda MG. Preoperative parameters for predicting early prostate cancer recurrence after radical prostatectomy. Urology. 2002; 59: 740-745. Ref.: https://goo.gl/yrtDCL

6. Feng TS, Sharif-Afshar AR, Wu J, Li Q, Luthringer D, et al. Multiparametric MRI improves accuracy of clinical nomograms for predicting extracapsular extension of prostate cancer. Urology. 2015; 86 : 332-337. Ref.: https://goo.gl/o54Y1i

7. Fuchsjager MH, Pucar D, Zelefsky MJ, Zhang Z, Mo Q, et al. Predicting post-external beam radiation therapy PSA relapse of prostate cancer using pretreatment MRI. Int J Radiat Oncol Biol Phys. 2010; 78: 743-750. Ref.: https://goo.gl/iY3yzh

8. Nguyen PL, Whittington R, Koo S, Schultz D, Cote KB, et al. Quantifying the impact of seminal vesicle invasion identified using endorectal magnetic resonance imaging on PSA outcome after radiation therapy for patients with clinically localized prostate cancer. Int J Radiat Oncol Biol Phys. 2004; 59: 400-405. Ref.: https://goo.gl/nMXL1v

9. Zakian $\mathrm{KL}$, Hricak H, Ishill N, Reuter VE, Eberhardt S, et al. An exploratory study of endorectal magnetic resonance imaging and spectroscopy of the prostate as preoperative predictive biomarkers of biochemical relapse after radical prostatectomy. J Urol. 2010; 184: 2320-2327. Ref.: https://goo.gl/hXborX

10. Clarke DH, Banks SJ, Wiederhorn AR, Klousia JW, Lissy JM, et al. The role of endorectal coil MRI in patient selection and treatment planning for prostate seed implants. Int J Radiat Oncol Biol Phys. 2002; 52: 903-910. Ref.: https://goo.gl/AgXF9h

11. Pugh TJ, Frank SJ, Achim M, Kuban DA, Lee AK, et al. Endorectal magnetic resonance imaging for predicting pathologic T3 disease in Gleason score 7 prostate cancer: implications for prostate brachytherapy. Brachytherapy. 2013; 12: 204-209. Ref.: https://goo.gl/LmruXi

12. Gondo T, Hricak H, Sala E, Zheng J, Moskowitz CS, et al. Multiparametric 3T MRI for the prediction of pathological downgrading after radical prostatectomy in patients with biopsy-proven Gleason score 3 + 4 prostate cancer. Eur Radiol. 2014; 24: 3161-3170. Ref.: https://goo.gl/SdCDT9

13. Wang L, Hricak H, Kattan MW, Chen HN, Kuroiwa K, et al. Prediction of seminal vesicle invasion in prostate cancer: incremental value of adding endorectal MR imaging to the Kattan nomogram. Radiology. 2007; 242: 182-188. Ref.: https://goo.gl/3k8DKb

14. Qian Y, Feng FY, Halverson S, Blas K, Sandler HM, et al. The percent of positive biopsy cores improves prediction of prostate cancer-specific death in patients treated with dose-escalated radiotherapy. Int J Radiat Oncol Biol Phys. 2011; 81: e135-142. Ref.: https://goo.gl/t5wviF

15. Chang ST, Westphalen AC, Jha P, Jung AJ, Carroll PR, et al. Endorectal MRI and MR spectroscopic imaging of prostate cancer: developing selection criteria for MR-guided focal therapy. J Magnetic Res Imag: JMRI. 2014; 39: 519-525. Ref.: https://goo.gl/coQzPL

16. Rischke HC, Nestle U, Fechter T, Doll C, Volegova-Neher N, et al. 3 Tesla multiparametric MRI for GTV-definition of dominant intraprostatic lesions in patients with prostate cancer--an interobserver variability study. Radiat Oncol. 2013; 8: 183. Ref.: https://goo.gl/ME3bpg

17. von Eyben FE, Kiljunen T, Kangasmaki A, Kairemo K, von Eyben R, et al. Radiotherapy boost for the dominant intraprostatic cancer lesion - a systematic review and meta-analysis. Clin Genitourin Cancer. 2016; 14: 189-197. Ref.: https://goo.gl/Jwv4sV

18. Zumsteg ZS, Spratt DE, Pei I, Zhang Z, Yamada Y, et al. A new risk classification system for therapeutic decision making with intermediate-risk prostate cancer patients undergoing dose-escalated externalbeam radiation therapy. European urology. 2013; 64: 895-902. Ref.: https://goo.gl/KCmuZi

19. Mouraviev V, Villers A, Bostwick DG, Wheeler TM, Montironi R, et al. Understanding the pathological features of focality, grade and tumour volume of early-stage prostate cancer as a foundation for parenchyma-sparing prostate cancer therapies: active surveillance and focal targeted therapy. BJU Int. 2011; 108: 1074-1085. Ref.: https://goo.gl/kqUfs6

20. Gomez-Iturriaga A, Casquero F, Urresola A, Ezquerro A, Lopez JI, et al. Dose escalation to dominant intraprostatic lesions with MRI-transrectal ultrasound fusion high-dose-rate prostate brachytherapy. Prospective phase II trial. Radiother and Oncol. 2016; 119: 91-96. Ref.: https://goo.gl/6JP1JP

21. Vigneault E, Mbodji K, Racine LG, Chevrette E, Lavallee MC, et al. Image-Guided high-dose-rate (HDR) boost localization using MRI/MR spectroscopy: a correlation study with biopsy. Cureus. 2016; 8: e795. Ref.: https://goo.gl/Tvjdvi

22. Gomez-Iturriaga A, Casquero F, Lopez JI, Urresola A, Ezquerro A, et al. Transperineal biopsies of MRIdetected aggressive index lesions in low- and intermediate-risk prostate cancer patients: Implications for treatment decision. Brachytherapy. 2016; 16: 201-206. Ref.: https://goo.gl/QvGkVn 